\title{
DEVELOPMENT OF A GEOGRAPHIC INFORMATION SYSTEM (GIS) TO IDENTIFY SPATIAL PATTERNS OF INDUSTRIAL CANCER RISKS: A PILOT STUDY ON ASBESTOS IN A PARIS SUBURB
}

Emilie Counil, ${ }^{1}$ Benjamin Lysaniuk, ${ }^{2}$ Charlotte Bijaye, ${ }^{3}$ Noémie Petitpas, ${ }^{3}$ Jean-Marc Fourès, ${ }^{3}$ GISCOP ${ }^{93}$ Team $^{2}{ }^{1}$ EHESP, Paris, France; ${ }^{2}$ Université Paris 13, Bobigny,

France; ${ }^{3}$ Université Paris 1, Paris, France

10.1136/oemed-2011-100382.363

Objectives Environmental and occupational exposures are usually treated as mutual confounders in the study of the association between toxic substances and health outcomes. Yet, research conducted on asbestos evidenced that occupational exposures may be considered as sentinel events with regard to environmental exposures. The project aims at studying asbestos-related "industrial cancer" risks through the mapping of neighbourhood and occupational risks of asbestos exposure in a historical and social perspective.

Methods Seine-Saint-Denis, a Paris suburb, was chosen as the pilot department for its industrial, immigration and socioeconomical history, and the availability of miscellaneous information. Different sources of data covering the last century have been collected (industrial, social, meteorological and sanitary) and integrated within a Geographic Information System. We mapped asbestos sites and identified "hotspots" of environmental contamination through atmospheric dispersion modeling.

Results To date, we took inventory of 111 former places which may have produced asbestos pollution of the working and/or general environments, collected quantitative and qualitative data to characterise this pollution potential, documented the presence of multiple carcinogens on 78 sites, and integrated indicators of social deprivation at the municipality level. We also crossed census data with the FIBREX database and identified municipalities which present current occupational exposure potential.

Conclusions We still have to describe the spatial distribution of cancer risk both for high (mesothelioma) and low (larynx, pharyngeal, stomach, colorectal cancers) etiological fractions sites. We will then explore spatial correlations between these different dimensions in order to produce knowledge on spatial and social clustering of occupational and environmental disadvantages. 